\title{
A fragilização do positivismo jurídico no contexto da sociedade globalizada
}

\author{
The fragilization of legal positivism in the context of the globalized society
}

\author{
Tatiane Burmann* \\ Daniel Rubens Cenci* \\ Vanderlise Wentz Baú ${ }^{*+*}$
}

\section{Resumo}

O artigo, a partir de uma revisão bibliográfica, apresenta uma crítica à concepção tradicional das fontes do Direito ligada ao positivismo jurídico. Entende-se que o referido pensamento resta insuficiente para capturar todas as diferentes modalidades de atos produtores do Direito passíveis de serem encontrados nos sistemas jurídicos contemporâneos, bem como que a primazia da lei enquanto fonte jurídica reduz a ideia de Direito ao positivismo legislativo, exaurindo a busca do justo e afastando o Direito e a justiça. Pois, embora o Direito continue a representar a ordem da sociedade e ainda se possam ter as mesmas perguntas e dúvidas jurídicas, as respostas já são outras.

Palavras-chave: Argumentação. Contemporaneidade. Crise. Lei. Positivismo jurídico.

\section{Abstract}

The article intends, from a bibliographical revision, to provide a critique to the traditional conception of the sources of the law linked to the legal positivism. It is understood that such thinking is insufficient to capture all the different modalities of law-producing acts that can be found in contemporary legal systems, and that the primacy of law as a legal source reduces the idea of the right to legislative positivism, the search for the just and turning away the right and justice. For although the right continues to represent the order of society and the same legal questions and doubts can still be answered, the answers are already different.

Keywords: Argumentation. Contemporaneity. Crisis. Law. Legal positivism.

\section{Introdução}

A sociedade contemporânea convive com uma enorme diversidade de sistemas e ordenamentos jurídicos - definidos por aproximações e características capazes de dar a esses uma identidade ou filiação às grandes famílias - e, por conseguinte, com a impossibilidade de se estruturar, mesmo que admitidos fundamentos comuns para o Direito, sobre bases de um suposto Direito universal. Chega-se a dizer que um dos legados da formação dos Estados modernos para a atualidade é o prestígio dos direitos nacionais, muito embora sua marca significativa seja o fenômeno da globalização combinado com a formação de um Direito comunitário, que inova as concepções registradas por noções fronteiriças de território e soberania.

Mestre em Direito pela Universidade Regional do Noroeste do Estado do Rio Grande do Sul - Unijuí. Doutoranda em Direito pela Faculdade de Direito da Universidade de Lisboa - FDUL. Lisboa-Portugal. E-mail: tatiburmann@gmail.com.

* Doutor em Meio Ambiente (UFPR). Mestre em Direito (UNISC). Professor do Mestrado em Direitos Humanos da UNIJUI. Pós-Doutor em Geopolítica Ambiental Latino-americana na USACH - Universidade de Santiago - Chile. Coordenador do Núcleo de Pesquisa do Departamento de Ciências Jurídicas e Sociais. Membro do Comitê de Pesquisa da UNIJUI. ljuí - RS - Brasil. E-mail: danielr@unijui.edu.br.

*** Mestre em Direito pela Universidade Regional do Noroeste do Estado do Rio Grande do Sul - Unijuí. Professora na área de Direito Público ministrando a disciplina de Direito Processual Civil na graduação e na pós-graduação da Universidade de Passo Fundo. Ijuí - RS - Brasil. E-mail: wentz@upf.br. 
Estudar as fontes dos sistemas jurídicos contemporâneos, diante dessa diversidade de direitos impressa pelo modelo nacional de ordens jurídicas, configura uma tarefa desafiadora. Tamanha tarefa é minimizada quando, ao invés de se adotar as diferenças do Direito de cada nação, investiga-se o Direito conforme suas relações com as grandes famílias ou sistemas jurídicos, ${ }^{1}$ por exemplo: a família romanogermânica, a common law, os direitos socialistas de tendência comunista, o Direito muçulmano, os direitos do extremo oriente, o Direito indiano, o Direito feudal, o Direito canônico, entre outros.

Nesse contexto, e sendo impossível realizar uma análise, à luz da teoria das fontes, de todos os grandes sistemas do Direito contemporâneo, elege-se o Direito ocidental, mais propriamente o atual sistema da família romano-germânica, como o universo empírico deste pequeno exame. Tal fato se deve por ser o nomeado, ao lado do Direito dos países do common law, não melhor do que os outros, mas, historicamente, mais adequado para regular certas relações de propriedade e de produção, a ponto de influenciar os ordenamentos jurídicos modernos e contemporâneos, e assumir posição de visibilidade na história do Direito em geral.

A respeito da persuasão do referido sistema, é possível afirmar que a teoria das fontes do Direito vigente na era contemporânea é uma herança do positivismo jurídico do século XIX. Mais que isso, ela expressa o pensamento liberal e individualista que predominava naquele contexto histórico pós-revoluções dos países da Europa ocidental e da América, qual seja, o da existência de um único modo de produção jurídica, a lei, sendo as demais meras fontes de conhecimento, sempre subsidiárias.

O presente texto, nesse sentido, pretende fornecer uma crítica da concepção tradicional de fontes do Direito ligada ao positivismo jurídico, por entender ser esse pensamento insuficiente para capturar todas as diferentes modalidades de atos produtores do Direito passíveis de serem encontrados nos sistemas jurídicos contemporâneos, bem como que a primazia da lei enquanto fonte jurídica reduz a ideia do Direito ao positivismo legislativo, exaurindo a busca do justo e afastando o Direito e a justiça.

Para tanto, em um primeiro momento, aborda-se a questão das fontes do Direito enquanto expressão do positivismo jurídico. Nessa linha, procura-se demonstrar a nova racionalidade jurídica decorrente do processo de codificação que, consolidada com as revoluções do século XVIII, relegou as outras fontes criadoras do Direito a um plano inferior e secundário em prol da supremacia da lei, por acreditar que ofereceria maior segurança para as relações jurídicas e, por óbvio, representaria e garantiria a ordem.

O segundo tópico versa sobre as fontes do Direito, herança do positivismo jurídico, enquanto fenômeno criador das normas e da ordem jurídica. Ressalta-se que a intenção não é detalhar as fontes em espécie, mas tentar demostrar que a lei, fonte por excelência do Direito, apesar de, no decorrer da história, ter sofrido um esvaziamento de substância ética, sempre garantiu o resultado da aplicação ao material jurídico e à respectiva interpretação das regras cartesianas para a direção do espírito - com preferência pela dedução, pela ordem e pela abstração como meios únicos para se chegar à ciência.

Por fim, o terceiro tópico - embora já se reconheça que, no mundo jurídico, o Direito não pode ser reduzido aos limites da lei codificada - tem como objeto o comportamento da primazia da lei frente os desafios do Direito atual. Isto porque o homem jamais conseguirá ser homem se, no mais fundo das suas convicções e de suas crenças, não vier a avistar o Direito natural.

A verdade é que, não obstante o empenho dos positivistas, estes resumem-se a identificar as normas que provêm das denominadas fontes do Direito, sem, no entanto, explorar a força das fontes do Direito na argumentação jurídica e os modos por meio dos quais essas interagem com as demais razões que podem, eventualmente, ser empregadas como fundamento de uma decisão judicial. Mas, de que vale o conteúdo do Direito, que não é algo previamente dado em normas inequívocas, mas algo para ser descoberto, sem uma prática construtiva e interpretativa de formação de significados por meio da argumentação? 


\section{Fontes do Direito enquanto legado do positivismo jurídico: só a lei e poucas leis}

O fenômeno da codificação do Direito é marca registrada do universo jurídico da Idade Contemporânea, sendo que seu início, na Europa, data do século XVIII. ${ }^{2}$ Decorrente dos princípios proclamados pela Revolução Francesa ${ }^{3}$ de modo particular e pelas revoluções liberais de modo geral, tem seu impulso atrelado à necessidade de criação de um sistema legal logicamente estruturado e capaz de oferecer, através de uma ordenação racional, condições para escapar ao 'caos' e ao obscurantismo medieval. ${ }^{4}$

Nesse sentido, a ideia desenvolvida pelas doutrinas racionalistas e, principalmente, pela escola do Direito natural em sua nova fase, conduziu para a criação de uma ordem jurídica de validez permanente, universal e baseada na razão, transformando a concepção de Direito como produto histórico na de Direito como produto racional. ${ }^{5} \mathrm{O}$ jusracionalismo do século XVIII desenvolveu, então, um sistema fechado, edificado no raciocínio e na demonstração lógica, que começou - em substituição às últimas fases jusnaturalistas, caracterizadas como sistemáticas e matemáticas - a orientar e ordenar as exposições do Direito positivo, passando a dominar os códigos e manuais positivistas até os dias atuais. ${ }^{6}$

Na esfera do Direito, especificamente, o jusracionalismo repercutiu de forma clara na ciência positiva, ainda desprovida de uma sistemática metodológica passível de atender não somente às novas reivindicações epistemológicas do mundo contemporâneo, mas também aos impactos de uma viragem na ordem social, política e econômica da época ${ }^{7}$. Chega-se a dizer, inclusive, que o período de ascensão do Positivismo na Europa continental correspondeu ao período de construção da denominada doutrina moderna das "fontes do Direito". Como explica Ferraz Júnior (2003, p. 223),

Segundo Antonio Escudero (1985), o Direito, com a Idade Contemporânea, tocado pelas ideias iluministas e racionalistas, experimentou dois grandes fenômenos que lhe atribuem uma marca própria dos períodos antecedentes: o constitucionalismo e a codificação. No que diz respeito ao processo de codificação, embora seus antecedentes tenham emergido já no século XVII, com o jusracionalismo atuante na defesa da possibilidade de organizar o Direito com base em princípios estabelecidos pela razão e expressos em regras claras e simples, o seu início, na Europa, data do século XVIII, com o desenvolvimento das ideias jusnaturalistas voltadas para a criação de uma ordem jurídica universal, imutável e racional.

A Revolução Francesa, mais do que um evento histórico enquanto passagem da modernidade para a contemporaneidade, desempenhou um papel simbólico arrebatador no imaginário dos povos europeus e do mundo que vivia sob sua influência no final do século XVIII. Luís Roberto Barroso (2009) é categórico em afirmar que coube a ela - e não à Revolução Inglesa ou à Americana - dar um novo curso para a história, que converteu não só a face do Estado absolutista em liberal, como também a da sociedade feudal e aristocrática em burguesa.

4 Na perspectiva de Rogelio Perez-Bustamante (1994), a codificação do Direito pode ser analisada sob três aspectos distintos, porém complementares: filosófico, político e socioeconômico. Para o primeiro aspecto, a codificação se sustenta na ideologia racionalista, propagando uma ideia de Direito 'todo complexo', de um sistema sem lacunas e harmônico que decorre do esforço da razão humana. Quanto ao segundo aspecto, a codificação é compreendida como um processo que contribui para a cristalização do Estado-nação, caracterizado pela centralização e uniformidade. Isto porque se o Estado nacional se edifica sobre as mesmas instituições, são necessários códigos uniformes e vigentes em todo território estatal capazes de contribuir para a sua unidade. Por fim, o viés socioeconômico deposita na codificação o elemento fortalecedor, ou, ainda, uma nova ordem jurídica passível de estabelecer um novo tipo de sociabilidade urgente na da sociedade burguesa em ascensão da época.

5 A respeito dessa mudança de concepção do Direito, são oportunos os ensinamentos de José Duarte Nogueira (2003, p. 241-261), para quem a evolução e a historicidade trazem em si o reconhecimento de que o Direito possui uma existência marcada por circunstâncias concretas, sujeitas a transformações ao longo do tempo. Nas suas palavras: "Falar-se na historicidade do direito significa ter consciência que a ordem jurídica se realiza na história, que está concretamente relacionada com um determinado meio social, político, econômico e cultural, nele nasce e se desenvolve [...] o particularismo da experiência jurídica só se revelará em todas as suas facetas, através da concreta apreensão histórica da sua realização".

$6 \quad$ Segundo Franz Wieacker (2004), o jusracionalismo é um dos muitos capítulos da história do Direito natural que retoma os tempos da filosofia helenística e persiste até o presente. Suas diversas manifestações históricas, desenvolvidas e conservadas ante a Filosofia e a Teologia, já que nem sempre a tradição do Direito natural esteve presente no cotidiano da técnica jurídica, sempre se fundamentaram na crença em uma ordem imutável e válida para todos, de modo a reger as relações intersubjetivas nos seus direitos e deveres dentro da sociedade. Na Idade Moderna, o Direito natural, sob a forma de jusracionalismo, vem suprir uma deficiência da ciência jurídica positiva no que diz respeito à nova imagem de mundo que se constrói depois do início do século XVII. Numa perspectiva mais idealista, o Direito natural moderno incidiu como fundamentação ética do Direito positivo, de modo que qualquer dissentimento com seus pressupostos era por ele combatido. Isto estimulou o jusracionalismo a se erguer contra a submissão do Direito da época, ou seja, ir de encontro a alguns princípios e fontes do Direito romano, bem como à submissão do pensamento jurídico às antigas 'autoridades' cultivadas pela Idade Média. Com sua visão de conjunto, o jusracionalismo contribuiu para estabelecer uma nova sistemática, impulsionando a elaboração de normas e instituições jurídicas originais, distintas daquelas legadas da tradição romana. Pode-se dizer que os métodos da Filosofia e das Ciências naturais se revolucionam, construindo uma nova forma de ver e interpretar a realidade: mais do que um processo de secularização do pensamento, o jusracionalismo se especifica como um método de conhecimento que se emancipa da Teologia moral e adquire autonomia. Destaca-se que, até esse momento histórico, a ciência jurídica já tinha experimentado a fase da exegese, do comentário e de um projeto humanista de sistematização frustrado.

Como bem coloca Nuno Espinosa Gomes da Silva (2000), a Europa passava por um momento de euforia racionalista, o qual teve fim com a Revolução Francesa, em 1789, dando-se início a um ambiente de anarquia e de reformismo: este levou, na intenção de defender o homem da sociedade, à afirmação da existência de direitos individuais, à declaração da liberdade e igualdade de todos os homens perante as leis, de soberania popular e nacional, de governo representativo, de separação dos poderes, de monarquia constitucional e parlamentar, e à afirmação da necessidade de constituições escritas. Adverte-se que o constitucionalismo, bem como as experiências constitucionais, não são objeto do presente estudo, a respeito do que se sugere a leitura da obra de Caetano (2015). 
a teoria das fontes, em suas origens modernas, reporta-se à tomada de consciência de que o Direito não é essencialmente um dado, mas uma construção elaborada no interior da cultura humana. Ela desenvolveu-se, pois, desde o momento em que a Ciência Jurídica percebe seu objeto (o Direito) como um produto cultural, e não mais como um dado da Natureza ou sagrado.

Ademais, o surgimento da racionalidade cartesiana aplicada ao Direito acentuou a crise do ius commune, notória desde o século XV. ${ }^{8}$ Primeiramente, colocou-se em causa a validade das normas, tanto do Corpus luris quanto do princípio da autoridade, este instituído no relevo dos doutores da ciência jurídica que apregoavam suas opiniões (opinio communis doctorum) sobre o ius commune. Na sequência, entendendose que o quadro vigente servia meramente como instrumento de adaptação dos velhos valores aos novos fatos, o que, na opinião de muitos, apenas escamoteava as manipulações patológicas da lei, havendo a sua rejeição. Diante dos seus visíveis sinais de esgotamento,

o novo ideal de objectividade incorpora a idéia de descoberta e deixa na penumbra a interpretatio e suas redes de sentido. A problemática da interpretação, os topoi, os standards valorativos e os esquemas lógicos utilizados desde os comentadores, deixam de ter lugar cativo nos tratados do jusnaturalismo racionalista (MARQUES, 2003, p. 369). ${ }^{9}$

A fim de atender aos propósitos de clareza matemática propugnados para a nova ciência jurídica, imperiosa se fazia uma ferramenta hábil de descobrir e reunir as regras de Direito por via racional, bem como dar-lhe um suporte de elevada organização lógico-formal. Nesse contexto, foi no código que a ambição jusracionalista se concretizou. ${ }^{10}$ Os códigos, portanto, representaram, na Idade Moderna, o instrumento através do qual o Direito natural da época interveio na organização do Direito positivo de uma vez por todas. ${ }^{11}$

A seguinte passagem de Luís Roberto Barroso (2007, p. 204-205), sustentada nos preceitos de Luigi Ferrajoli (2003), sintetiza, acertadamente, o referido processo de transformação histórico:

No Estado Pré-Moderno, a formação do Direito não era legislativa, mas jurisprudencial e doutrinária. Não havia um sistema unitário e formal de fontes, mas uma multiplicidade de ordenamentos, provenientes de instituições concorrentes: o Império, a Igreja, o Príncipe, os Feudos, os Municípios e as Corporações. O direito 'comum' era assegurado pelo desenvolvimento e atualização da velha tradição romanística e tinha sua validade fundada na intrínseca racionalidade ou na justiça do seu conteúdo. Veritas, non

8 Conforme as lições de Mario Reis Marques (2003), o humanismo foi o primeiro movimento intelectual que endereçou críticas ao Direito e à ciência jurídica baseada no ius commune. A multiplicidade de fontes (doutrina, jurisprudência, leis e costumes) e o excesso de casuísmo eram alguns dos objetos dos ataques humanistas que, porém, não chegaram a lograr uma verdadeira mudança no "figurino" das fontes jurídicas e na ciência do Direito, apenas obtida com o jusnaturalismo racionalista.

9 Ainda, no que diz respeito à crise do ius comunne de uma forma mais genérica, José Reinaldo Lima Lopes (2002, p. 215), historiador do Direito brasileiro, leciona que a nova subjetividade filosófica e o empirismo científico vigentes na modernidade foram de encontro àquela jurisprudência tradicional que se materializara no ius commune. Justifica sua afirmação no fato de que a filosofia dos séculos XVI e XVII colocou em dúvida a autoridade exterior à razão. Inclusive, suspeitou dos sentidos e intuições, pois, de acordo com o próprio pai do pensamento cartesiano, Descartes, poderiam nos induzir a erro. Nesta linha, a tradição escolástica estaria eivada de equívocos, e, portanto, já não contribuiria para a construção do conhecimento. Consequentemente, há a grande valorização da descoberta e da razão especulativa e reflexiva, que atinge o auge com o pensamento de Kant, ao afirmar que "há categorias completamente ideais, pensadas, a priori, anteriores à experiência e aos sentidos, pelas quais o sujeito pensante pode pensar o mundo". Como se não bastasse, o empirismo moderno, e neste destaca-se a figura de Hume, vem igualmente indagar até que ponto os sentidos podem ser fonte do saber, visto que, para se obter um conhecimento 'verdadeiro', há de se experimentá-lo, medindo-o, quantificando-o e calculando-o; rejeitando, por conseguinte, a tradição escolástica até então vigente, uma vez que lhe faltava raciocínio abstrato e experimental sobre os fatos e coisas existentes.

10 No que diz respeito a Portugal, é a Revolução de 1820 que marca o começo do domínio do pensamento liberal, com a promulgação da Constituição de 1822. Embora, conforme já dito, as constituições não estejam no âmbito do estudo, tratando-se de fontes, interessa consignar que o conceito de lei, até então, era a vontade do monarca, por qualquer vontade manifestada. Com a codificação, passa a ser a vontade dos cidadãos declarada pela unanimidade ou pluralidade dos votos dos seus representantes juntos em Cortes, precedendo discussão pública. "O deslocar da soberania, do rei para a Nação, faz com que, no plano das fontes, paralelamente, a vontade do rei seja substituída pela vontade dos cidadãos" (SILVA, 2000 , p. 417). Ver na obra referida o tópico movimento de codificação em Portugal, p. 417 e ss. Ainda sobre a codificação em Portugal, pode ser consultada a nota de Gilissen (2008, p. 461).

11 Adverte-se que o Código não é uma criação exclusiva da modernidade. A palavra "código" deriva do termo latino codex, cujo significado representava, em seu início, apenas a ideia de um volume de folhas de pergaminho unidas ou costuradas. Na passagem do século III para o IV d.C., o termo adquire semântica propriamente jurídica, significando as compilações das leis imperiais romanas, a exemplo do Código Teodosiano ou Justiniano. $\mathrm{Na}$ Idade Média, evolui-se para um conceito mais abstrato do termo, que passa a designar as obras jurídicas marcadas por certa uniformidade de elaboração e organização formal. Hoje, depois da influência das ideias racionalistas e iluministas da segunda metade do século XVIII, pode-se designar Código como uma lei de conteúdo homogêneo em face da matéria que, de forma sistemática e articulada, expressa em uma linguagem precisa a regulação de todos os problemas da matéria unilateralmente delimitados (TOMAS Y VALIENTE, 2001). 
auctoritas facit legem é a fórmula que expressa o fundamento jusnaturalista de validade do direito pré-moderno [...]. O Estado de Direito Moderno, assinala ainda Ferrajoli, nasce sob a forma de Estado Legislativo de Direito. Graças ao princípio da legalidade e às codificações que lhe deram realização, uma norma jurídica não é válida por ser justa, mas por haver sido 'posta' por uma autoridade dotada de competência normativa. Auctoritas, non veritas facit legem: este é o princípio convencional do Positivismo Jurídico. Com a afirmação do princípio da legalidade como norma de reconhecimento do Direito existente, a Ciência Jurídica deixa de ser uma Ciência imediatamente normativa para converter-se em uma disciplina cognoscitiva, explicativa do direito positivo, autônomo e separado em relação a ela. A jurisdição, por sua vez, deixa de ser produção jurisprudencial do Direito e se submete à lei como única fonte de legitimação.

É possível afirmar, assim, que a teoria contemporânea das fontes do Direito, na qual se destaca a primazia da lei, é um legado do positivismo jurídico do século XIX, pois, para a concepção positivista, no que diz respeito às fontes do Direito, somente existia um modo de produção jurídica, a lei - as demais eram consideradas meras fontes de conhecimento, sempre subsidiárias. Nesse horizonte, Ollero (2005) avalia a teoria das fontes do Direito como expressão de uma determinada ideologia acerca da relação entre os valores "justiça" e "segurança", que poderia ser localizada nos Códigos continentais do século XIX.

A ambição racionalista, logo, não era apenas sistematizadora e inovadora da matéria jurídica. Como bem exacerba Mário Reis Marques (2003, p. 07), tratava-se verdadeiramente de uma nova cultura jurídica que, edificada, vem a suprir aquela do ius commune. Consideram-na, inclusive, como um novo sistema, contrário e alternativo à opinio communis doctorum - último método da ciência jurídica que gravitava na órbita da cultura do ius commune -, girando em torno da redescoberta do Corpus luris Civilis. Enquanto naquele a atividade do jurista mais valorizada era o labor doutrinal e jurisprudencial, no período da codificação, é a figura do legislador que assume centralidade: "O Estado, através do poder legislativo, passa a observar a criação do direito, introduzindo profundas alterações no papel até aí desempenhado pelos juristas" (MARQUES, 2003, p. 07).

Essa nova racionalidade jurídica atribuiu ao Código a melhor forma de expressão do Direito e, ao legislador, o papel de criá-lo, fortalecendo a tese de que a lei oferece maior segurança para as relações jurídicas. Ainda em torno do processo de codificação e na busca da mencionada segurança jurídica, desenvolveu-se uma tendência unificadora das leis de uma mesma sociedade - rompendo com a racionalidade da tradição romanística e com os vícios do Antigo Regime. O Código se tornou depositário das expectativas de unificação do Direito vigente em âmbito nacional, uma vez que a existência de leis distintas dentro de um mesmo território propiciava a "desordem" e o "caos" em sobreposição à ordem jurídica - ou seja, o Direito justo, enquanto produto da razão natural, deve ser universal na sua vigência (TOMAS Y VALIENTE, 2012). Dessa forma, os juristas, os ilustrados e os políticos do liberalismo, tomados por uma razão otimista e radical, acreditavam que o Direito codificado seria capaz de abarcar, de um modo justo do ponto de vista do conteúdo, toda a realidade: uma nova ordem, de caráter natural, apreensível pela razão e capaz de fornecer leis universais e imutáveis para toda a sociedade.

Não restam dúvidas de que o processo de codificação marcou uma nova fase na história jurídica. Como bem acentua António Manuel Hespanha (1998), o processo de codificação procedeu, para além de um novo esboço das instituições - correspondente à ordem social burguesa, liberal, democrática, em superação à velha ordem absolutista e estamental -, a instituição de uma tecnologia normativa fundada na generalidade e na sistematicidade, adequada à aplicação do Direito mais cotidiano e mais controlável pelo novo centro do poder.

Atualmente, é notória a limitação de tal pretensão. Os problemas jurídicos que assolam o mundo já não são mais genéricos e cotidianos. No entanto, as fontes do Direito, na perspectiva positivista, são normalmente descritas como se fossem condições necessárias e suficientes para a criação e solução do Direito. 


\section{Fontes do Direito na época contemporânea: ${ }^{12}$ a lei no centro da ordem jurídica}

Entre as fontes do Direito da época contemporânea, a lei é, desde os finais do século XVIII, a principal, ou mesmo a única, fonte teoricamente reconhecida pela maior parte dos juristas no decurso do século $\mathrm{XIX}$, que a agrupam sob a designação de positivismo legalista. ${ }^{13}$ Embora a partir do século XX tenha se verificado uma reação ao costume, à jurisprudência, à doutrina e mesmo à equidade ou aos princípios gerais do Direito, uma parte importante na formação do Direito, o positivismo domina ainda largamente as práticas do Direito. ${ }^{14}$

A colocação da lei no centro da ordem jurídica tem consequências precisas no que tange à hierarquia dos poderes do Estado: o único poder do Estado é o legislativo, restando aos demais apenas funções de mera execução. Nesse cenário, a posição criativa do juiz, que obscurecia a aplicação da vontade individual e revelava direito ao mundo dos profanos, é submergida pelo princípio da legalidade. Em outras palavras, a lei passa a ser teorema de onde o aplicador deve extrair as devidas consequências através de raciocínios silogísticos de mera subsunção.

Nesse sentido, entende-se que o Direito legislativo é completo e autossuficiente - e, na existência de lacunas ou dúvidas, deve-se sempre recorrer e confiar-se nos recursos do próprio texto -, como se se tratasse de uma gramática generativa capaz de alargar com sucesso o esquema lógico que encerra, adaptando-o a novas situações. Não é à toa que muitos autores modernos ensinavam

[...] não só que a perpetuidade era da natureza da lei, mas que era da sua essência, não devendo chamar-se lei senão por analogia um preceito temporário. Para o recto governo da república são necessários os preceitos estáveis, e por isso a verdadeira lei, uma vez promulgada, deve vigorar até que nova lei a venha revogar no todo ou em parte, ou dispensar a sua aplicação nalgum caso particular, o que só se deve ter lugar quando para tal haja justa causa (MONCADA, 2004, p. 222). ${ }^{15}$

12 Oportuno, em sede de preliminar, advertir que as fontes do Direito contemporâneo se classificam em materiais e formais. Na concepção de Carnelutti (1955), ao passo que as primeiras correspondem à ideia de fatores e circunstâncias materiais que condicionam e impulsionam a origem da norma jurídica (como os estudos da Sociologia Jurídica, da Ciência Política ou da Economia), as segundas associam-se a dispositivos juridicamente válidos, através dos quais as normas jurídicas se exteriorizam. É nestas que se busca identificar o lugar das normas que são introduzidas no ordenamento jurídico, fixando novas regras de conduta social. Assim, elas se subclassificam em duas grandes categorias: a) fontes formais estatais - resultado de processos legislativos, da atividade do legislador estatal, ou, ainda, da atividade jurisdicional do Estado e, por conseguinte, englobam as leis, sob a forma de legislações ou códigos, e a produção jurisprudencial; e b) fontes formais não-estatais - originárias de processos não controlados pelos poderes do Estado, como as práticas costumeiras, os estudos científicos do fenômeno jurídico ou os poderes negociais de indivíduos ou grupos de indivíduos organizados; logo, encaixam os costumes, a doutrina e as normas jurídicas particulares e ou de grupos individualizados, a exemplo dos sindicatos. Nesse contexto introdutório, é cabível lembrar, ainda, que há distinção entre fonte do Direito (fontes de criação) e fonte histórica do Direito (fontes de conhecimento). A fonte jurídica associa-se à maneira como as normas se manifestam ou se exteriorizam e corresponde à própria norma e princípio que vigoram como prescrições jurídicas em determinada época, enquanto que a fonte histórica do Direito se refere ao meio de conhecer o Direito. Sobre o tema, ver obras como as de Latorre (2002); Caetano (1992). Por fim, breve exposição permite esclarecer que, como o presente tópico tem como tema central a lei, na sequência, quando se falar em fonte do Direito, tratar-se-á, de fonte formal do Direito.

13 Segundo Moncada (2002), a predominância da lei positiva como fonte do Direito é consequência da modernidade e do pensamento iluminista. A lei passa a ser o espelho do Direito pelo que ela é e apenas ela que o constitui originariamente. Como a lei é uma norma racional, é sistematizável sendo a codificação da sua própria natureza.

14 Conforme Gilissen (2008, p. 415-416), a teoria da separação dos três poderes não conhecia outra fonte do Direito que não fosse a lei. O costume, pelo menos na aparência, deixou de desempenhar qualquer papel como fonte do Direito desde a época da Revolução Francesa, eis que representava um dos traços característicos do Antigo Regime, tendo sido varrido pela legislação revolucionária e pelos códigos napoleônicos - a exceção da relação entre o Estados ou entre cidadãos de Estados diferentes, pela inexistência de um órgão legislativo nesse sentido, ou seja, de um direito internacional. A jurisprudência, interpretando os textos legais, cria verdadeiramente Direito novo, sobretudo a partir de 1860-1880, e contribui para unificar o Direito. Por fim, a doutrina tomou lugar central na evolução do Direito, tanto pela massa enorme de obras jurídicas como pela qualidade do trabalho de análise e de interpretação das normas jurídicas. A importância da doutrina como fonte suplementar do Direito, embora menor do que a jurisprudência, é cada vez mais considerável. Numa síntese simplificadora, pode-se dizer que atualmente o estado dessa questão de reconhecimento de fontes se resume a três grandes categorias teóricas e práticas do Direito: a postura monista (o Direito como produto da criação exclusiva do Estado), a postura dualista (o Direito tem, além da lei positivada, sua expressão nos costumes, embora de maneira limitada) e a postura pluralista (o Direito pode ter origem num conjunto variado de fontes, como a lei, os costumes, a jurisprudência, as práticas extrajudiciais, entre outras). A respeito da passagem da ordem monista para a ordem pluralista, a qual foi determinada por uma nova concepção de Estado, consultar a obra de Nogueira (1996, p. 36 e ss). Reitera-se que as fontes do Direito em espécie não são tema do presente estudo, para o que se sugere ver as obras de John Gilissen, ora referida; Caetano (1992) e David (1996).

15 Ainda com relação à estabilidade da norma, Moncada (2002, p. 215) é convicto de que "muitos problemas momentosos da história do direito e das ideias jurídicas só podem ser bem postos, e por consequência só podem ser solucionados, quando se tenha presente o dogma da estabilidade da lei". Na mesma linha, Nogueira e Santos (1996, p. 11 e ss) observam a existência de princípios imutáveis e transcendentes de justiça e, por conseguinte, de uma lei eterna segundo a terminologia tomista, acompanhada de cepticismo quanto à sua plena cognoscibilidade e pelo homem. 
O pensamento moderno conduziu à identificação da legitimidade com a legalidade, timbre de todo positivismo jurídico. ${ }^{16}$ Nessa circunstância, a lei passa a ser a fonte do Direito por excelência, em que a supremacia política do parlamento corresponde à supremacia jurídica da lei como fonte daquele. $\mathrm{O}$ desenvolvimento dessas concepções levou a confundir a lei com o princípio da legalidade, provocando situações de manifesta ilegitimidade ética, a qual o positivismo foi incapaz de conter.

Diante de tal cenário, necessário se fez apresentar uma lei como um puro e simples instrumento racional politicamente descomprometido, ou seja, neutro. Eis quando o racionalismo jurídico traçou a lei como uma norma puramente jurídica, sem intenções políticas que embaraçariam a respectiva racionalidade, formal e sistemática. O fim da lei passou a ser irrelevante - isto quer dizer que era a formal racionalidade legislativa que garantia a indiferença da lei perante a sociedade, assim abrindo espaço para a manutenção do status quo. A lei cumpria, certamente, na sociedade burguesa uma função política, precisamente a de libertar o Estado, mas, para que assim fosse, tinha que se apresentar como um instrumento puramente jurídico, na sombra ficando sua sempre presente intencionalidade política e os interesses definidos a que servia (MONCADA, 2002). ${ }^{17}$

A situação descrita era a única capaz de desvincular a lei da sua função política. Foi marcada por um Estado de legalidade ao invés de Estado de Direito, pela substituição da justiça em face da segurança - esta manifestada através de normas legislativas mensuráveis e previsíveis, aplicadas por juízes sem qualquer possibilidade de argumentação - e por uma discreta, mas evidente, intencionalidade política, mais garantística do que conservadora, avessa ao compromisso e aos valores que encerrava e traduzia. Perdurou durante todo o século XIX e nas primeiras décadas do século XX, e é completamente oposta a tendência atual.

A atualidade volta a ser marcada por tendências da modernidade, contudo, não iluminista. A permanência das ideias do Direito próprio da modernidade, em que as considerações de eficácia sobrepunham-se às de legitimidade, ou, melhor dizendo, identificavam-se, levou à caracterização de um Estado de Direito no qual os direitos dos cidadãos são, apenas, os que a lei positiva conceder (CAETANO, 2015). Todavia o ponto de partida da lei, agora, não é mais o Estado, como para as Luzes, mas a comunidade cultural. De tal modo, a noção de lei cede às características que lhe deram para as influências iluministas e que dela fizeram uma norma ditada pela autonomia individual, democraticamente elaborada e racionalmente legitimada, para se encontrar e se legitimar no circunstancialismo constitutivo próprio da história e da cultura, necessariamente diferenciado em cada comunidade e adequado a cada situação concreta, dando voz ao dado existencial de certa realidade histórica (CAETANO, 2015).

Com isso, é fato que a lei estabelece, originariamente, o Direito, o qual, por sua vez, reduz-se a ela, e também que a ideia de estabilidade da lei não desapareceu. Porém, com a marcha da civilização, notase, para além da definição cada vez mais precisa de círculos concêntricos legais, que a legalidade passou a ser a fórmula vazia do arbítrio do legislador, pois a memória repetida das normas que rege as soluções se traduz na "lei a quem chamam direito ignora a pessoa que não tem poderes, nem representações, nem interesses. A lei que fixa a ordem das coisas impostas pelos poderosos" (PINTO, 2015, p. 116). ${ }^{18}$

\section{0 paradigma da primazia da lei e os desafios do Direito atual}

A verdade é que essa primazia da lei positivada como fonte por excelência, resultado do racionalismo e do limite de poderes pela via da legalidade do Direito contemporâneo, trouxe uma série de condicionantes de caráter extrajurídico. Da mesma forma que o sistema de fontes não é fruto do acaso ou do capricho,

\footnotetext{
16 Ver capítulo XI, Da espécie de liberdade que se encontrava no Antigo Regime e de sua influência sobre a Revolução, do Livro Segundo, da obra de Tocqueville (1997).

17 Nessa linha, ver a obra de Kelsen (1998).

18 Dentro dessa perspectiva, Ruy de Albuquerque e Martin de Albuquerque (2005) chamam a atenção para a necessidade de se determinar os elementos translatícios, fixados pela tradição, ou seja, de se apurar quanto numa dada ordem jurídica não corresponde ao criado contemporaneamente, mas que foi herdado de épocas anteriores, para, assim, conseguir responder aos problemas concretos e fazer uma distinção de soluções - muito embora as ordens jurídicas continuem a ser tidas como válidas para problemas comuns ao período em causa como o foram para os seus antecedentes, tratando-se de uma vivência da norma pela incapacidade de renovação. Tem-se, nesse caso, uma dualidade de fontes: a fonte considera como o Direito se constitui e a ordem jurídica que se formaliza.
} 
mas, sim, efeito de múltiplos fatores políticos, sociológicos e ideológicos, através dele igualmente deriva um conjunto de ideias e de fatos dominantes na comunidade a qual se aplica. No caso, o predomínio da lei como fonte repercute na intensidade crescente do poder do Estado e em sua organização e atividades perante as normas espontâneas de criação do Direito. Por conseguinte, em soluções inadequadas à concretização da justiça. ${ }^{19}$

Ora, o Direito reduzido à lei positivada, a qual tem vocação estabilizadora, tende a se estabilizar no tempo, bem como nos fatos. Resta, inevitavelmente, desatualizado em face da realidade concreta, em constante mutação. Tem-se um esgotamento da racionalidade frente aos novos modos de ser, os quais exigem novas regras. Assim, aquele entusiasmo que estava no centro das revoluções liberais e no íntimo das codificações, no sentido de que a lei é a forma mais adequada e segura de expressar o Direito e assegurar a solidez das relações sociais, finda por ser a razão de seu próprio perigo nos dias atuais. ${ }^{20}$

Tal situação faz repensar a postura do Estado na condição de fonte exclusiva de criação e aplicação do Direito. Os sintomas de sua insuficiência em abranger a realidade pelos princípios e preceitos dos códigos já podem ser sentidos, do mesmo modo que sua deficiência já é evidente na tentativa de monopolizar a administração da justiça ante a infinidade de causas que não consegue solver, seja no aspecto formal, seja no sentido substancial.

De acordo com Vaz Serra, para a realização da paz jurídica, necessário se faz afastar a tentação política e substituir a solução legal pela solução justa, a lei escrita pela lei moral, o arbítrio do legislador pelo próprio arbítrio. ${ }^{21} \mathrm{~A}$ justiça, assim, reaparece como valor absoluto, como ideia pura, para a qual tendem ideais tão vigorosos e irresistíveis que podem impor ao intérprete o desrespeito da própria lei. Eis um dos mais melindrosos problemas da Ciência do Direito: saber se seria lícito, em alguma hipótese, aos executores da lei ou aos simples cidadãos, desobedecer à lei em nome de uma Justiça superior.

Já Marcello Caetano (s./d., p. 158), apesar de igualmente entender que o Direito não pode estar associado à lei positivada, respeita a legalidade, ou seja, o Direito positivo, por acreditar que "uma lei, mesmo quando seja má, é preferível à ausência de lei nos casos em que da sua falta resulte o capricho nas resoluções da autoridade e a incerteza dos direitos dos indivíduos". E acrescenta: "a lei, estabelecendo critérios gerais e abstratos para a solução de casos concretos, é sempre uma garantia de igualdade e, portanto, de Justiça, ainda que essa Justiça seja meramente relativa e formal". (CAETANO, 2015).

Nesse sentido, pode-se dizer que a tendência codificadora, para além de gerar um afastamento entre o Direito e a justiça, ocasionou a atual crise enfrentada pelos órgãos judiciais, atingindo, inclusive, a própria credibilidade do Direito enquanto forma de regulação e resolução de conflitos. Segundo Boaventura de Sousa Santos (1997), vive-se um "declínio da litigiosidade", reflexo da descrença no judiciário, da dificuldade do acesso à justiça e da busca de formas alternativas de resolução de litígios.

No entanto, embora já reconhecida, no mundo jurídico, a ineficiência do Direito reduzido aos limites da lei codificada, ainda não há uma superação completa do paradigma vigorante. O que se tem, quando considerada suas limitações e deficiências perante esse quadro, é uma atenuação dos excessos, mas longe de representar a emergência de uma nova forma de pensar, criar, organizar e aplicar o Direito. ${ }^{22}$

19 Segundo Manuel Rodrigues Júnior, citado por Chorão (2014, p. 148), “o Estado é a fonte de toda a regra normativa, toda a positividade individual está subordinada ao Estado e, por isso, por ele há-de ser modelada. Nenhum poder estranho, nenhuma regra universal, nenhum princípio que não tenha sido gerado ou assimilado dentro das fronteiras". Ver também, sobre o assunto, as obras de Latorre (2002) e Pinto (2015).

20 Cabível o relato do ministro da Justiça de Portugal, Vaz Serra, transcrito por Chorão (2014, p. 149): no seu perfil de juiz, "disse não ser em princípio senão o executor da lei e que por isso mesmo tinha o dever de se submeter aos juízos de valores imanentes do direito positivo, por muito injustos que lhe parecessem".

21 Em sentido oposto está a posição de José Maria Vilhena Barbosa de Magalhães, que reconhece o fato de se estar atravessando uma época de crise da lei. No entanto decorrente do desprestígio e desrespeito pelos cidadãos, pelos tribunais, interpretando-a livremente, ou preferindo-lhe a equidade, a moral e a justiça, e pelo próprio legislador - os poderes públicos, o Estado - maior razão há para não agravar essa crise com tal sistema de contínua instabilidade. Tanto o entendimento de Vaz Serra quanto o de Maria Vilhena Barbosa de Magalhães podem ser encontrados na obra de Luís Bigotte Chorão (2014).

22 No que diz respeito a uma nova forma de pensar, criar, organizar e aplicar o Direito, cabe destacar a existência de um conjunto teórico de produções, não homogêneas, mas hábeis a gerar um conhecimento do Direito que enseja o seu questionamento social mais profundo, firmado em torno de críticas ao modelo positivista como centro do sistema de fontes atual. Neste conjunto de novos olhares para o Direito, segundo Clèmerson Merlin Clève (2001, p. 79), pode-se encontrar um ponto de interseção epistemológica que aqui merece destaque: o objetivo de "estabelecer, concreta e positivamente, a cientificidade de um saber interrogante, crítico e questionador". 
Afora a urgência em se redefinir o sistema de fontes do Direito contemporâneo, não se pode pensar na atualidade como um período que mantém traços uniformes desde a Revolução Francesa, pelo contrário, sua marca são mudanças consideráveis. Logo, não se pode querer o mesmo Direito para solver problemas nunca vistos. Nesse contexto, alguns pensadores do século XX apontam que a história da contemporaneidade vem sendo traçada por sobressaltos violentos - efeitos, principalmente, das grandes guerras e das barbáries humanas -, e, consequentemente, por um desencanto que assola o projeto político e jurídico moderno, hoje incapaz de gerir muitos dos seus males. ${ }^{23}$

Não causa estranheza essa avaliação pessimista que os mais diversos intelectuais têm da atualidade, revelada a cada dia no esgotamento dos modelos vigentes. A expectativa que animava o lluminismo e que construiu as bases do Estado e do Direito contemporâneo é hoje impraticável. A história, com suas experiências do século XX, já demonstrou que não é estável, muito menos linear, ou seja, que apesar da sua constante mutação, não se dá sucessivamente para o avanço e para a evolução, rumo ao que pode existir de melhor ou mais desenvolvido no momento. Da mesma maneira, a ideia matemática e de previsão, núcleo do racionalismo que animou a tendência codificadora, também se curva aos acontecimentos imprevisíveis ou incontroláveis dos novos tempos.

Diante do atual cenário pintado, e vivenciado, muito se tem questionado, como não poderia ser diferente, até que ponto a racionalidade jurídica da codificação estatal e do controle do poder pelo Direito conseguem responder e corresponder aos problemas da atualidade. Por todos esses novos desafios do Direito e das demais ciências é que muito se tem falado em crise do Direito, a qual nada mais é do que uma crise do paradigma ${ }^{24}$ jurídico das revoluções liberais.

\section{Conclusão}

A ciência, no pensamento ocidental moderno, foi idealizada como forma de produção de conhecimento legítimo, sujeito a métodos rigorosos, abrangido pela razão humana e distinto da realidade através de dialéticas como a do "verdadeiro-falso", do "refutável-irrefutável", do "laico-religioso", e, em especial, da "ordem-desordem". Assim, ela seria encontrada nas leis que regulam o funcionamento das coisas, resultando no próprio controle, leia-se ordem, da natureza.

Nesse axioma, o Direito foi corrompido a uma forma de racionalidade que incluía as regras lógicas das ciências físicas, simbolizada no mito próprio da cultura jurídica do normativismo positivista. Dessa forma, à luz da dialética ordem-desordem, caberia ao direito garantir a ordem mediante leis lógico-formais, extraídas da razão humana e isentas de influências extrajurídicas. Ou, ainda, ao passo que a ordem significava um estado de unidade, a desordem se dava quando os elementos constituintes de um determinado conjunto se comportassem como se dele não fizessem parte.

Com as descobertas da ciência no início da contemporaneidade, uma nova concepção de racionalidade científica, fundamentada, não mais na sobreposição da ordem à desordem, como na modernidade, mas sim, no fato de que ambas, na realidade concreta, são inseparáveis, passou a ser admitida e a definir a epistemologia contemporânea. Esta, entretanto, não adveio de revelações abstratas, pelo contrário, decorreu da constatação de um paradigma em dificuldades de ajustar-se à realidade, que, por sua vez, pôs em causa sua estabilidade e validade.

Das contradições de paradigma vigente, passou-se a falar, a partir de meados do século XX, em crise do Direito, a qual, se observada do ponto de vista da historicidade, está intrinsecamente ligada a crises históricas dos variados aspectos da vida social. Nessa linha, a ideia de lei positivada, enquanto fonte

\footnotetext{
É possível observar tal posicionamento nas obras da filósofa Arendt (2006) e do historiador Hobsbawm (1995).

Segundo Thomas Kuhn (1997), uma crise de paradigma representa uma oportunidade de mudança. Logo, para o surgimento de novas teorias, faz-se imprescindível uma crise prévia. No caso em questão, muitas teorias vêm aparecendo em resposta ao dogmatismo formalista que implicava ao Estado o status de única fonte válida do Direito, e que tem na lei a sua única e legítima forma de criação. Essas reações têm pontos de vista diversos, mas todas se conjugam no esforço de descrever o momento atual da racionalidade jurídica como um momento de crise e de sugerir possibilidades a essa racionalidade.
} 
inesgotável de ordem, paz e equilíbrio, não se sustentou diante da realidade concreta, global e mutante, e dos problemas enfrentados no alvorecer do século XXI, inatingíveis e incontroláveis pelas concepções racionalistas e positivistas vigorantes. Pois, embora o Direito continue a representar a ordem da sociedade e ainda se possam ter as mesmas perguntas e dúvidas jurídicas, as respostas já são outras.

O que importa, portanto, não é abandonar as perguntas de partida que sempre animaram o Direito, mas sim buscar novas respostas, pois os desafios são os pontos de chegada da atualidade, estabelecendo uma responsabilidade para com o condicionamento do futuro. Até lá, ainda se faz preferível a dura lex, sed lex, do que a sujeição ao capricho e ao bom ou mau senso do juiz ou do tribunal. ${ }^{25}$

\section{Referências}

ALBUQUERQUE, Ruy de; ALBUQUERQUE, Martim de. História do direito português: 1140-1415. Lisboa: Sintra, 2005. v. I.

ARENDT, Hannah. Origens do totalitarismo. Trad. Roberto Raposo. São Paulo: Companhia das Letras, 2006.

BARROSO, Luís Roberto. Curso de direito constitucional contemporâneo. São Paulo: Saraiva, 2009.

BARROSO, Luís Roberto. Neoconstitucionalismo e constitucionalização do Direito (o triunfo tardio do Direito Constitucional no Brasil). In: SOUZA NETO, Cláudio Pereira de; SARMENTO, Daniel (Org.). A constitucionalização do direito: fundamentos teóricos e aplicações específicas. Rio de Janeiro: Lumen Juris, 2007. p. 203-249.

BARRETO, António (Org.). Justiça em crise? Crise da justiça. Lisboa: Publicações Dom Quixote, 2000.

CAETANO, Marcello. História do direito português: fontes - direito público [1140-1495]. Lisboa: Verbo, 1992. v. I.

CAETANO, Marcello. Manual de ciência política e de direito constitucional. Coimbra: Almedina, 2015. t. 1.

CAETANO, Marcello. Páginas inoportunas. Lisboa: Bertrand, [s./d.].

CARNELUTTI, Francesco. Teoría general del derecho. Madrid: Revista de Derecho Privado, 1955.

CHORÃO, Luís Bigotte. Política de justiça: uma indagação histórica. In: BARBAS HOMEM, António Pedro (Coord.). As conferências do centro de estudos judiciários. Coimbra: Almedina, 2014. p. 117152.

CLÈVE, Clèmerson Merlin. O direito e os direitos: elementos para uma crítica do direito contemporâneo. São Paulo: Max Limonad, 2001.

DAVID, René. Os grandes sistemas do direito contemporâneo. Trad. Hermínio A. Carvalho. 3. ed. São Paulo: Martins Fontes, 1996.

ESCUDERO LÓPEZ, José António. Curso de historia del derecho. Madrid: Solana, 1985.

FERRAJOLI, Luigi. Pasado y futuro del Estado de Derecho. Traducción de Pilar Allegue. In:

CARBONELL, Miguel (ed.). Neoconstitucionalismo(s). Madrid: Trotta, 2003. p. 13-29.

FERRAZ JÚNIOR, Tércio Sampaio. Introdução ao estudo do direito: técnica, decisão, dominação. 4. ed. São Paulo: Atlas, 2003.

GILISSEN, John. Introdução histórica ao direito. Trad. A. M. Hespanha e L. M. Macaísta Maheiros. 5. ed. Lisboa: Fundação Calouste Gulbenkian, 2008.

GOUVEIA, Jorge Bacelar. A constituição e o direito justo. Disponível em: <https://run.unl.pt/ bitstream/10362/15148/1/JBG_ConstituiçãoDireitoJusto.pdf>. Acesso em: 12 jun. 2016.

25 Ver o capítulo intitulado No regresso às regras jurídicas como fonte de direito, o eterno retorno ao direito romano, da obra de Pinto (2015). 
GOUVEIA, Jorge Bacelar; PIÇARRA, Nuno (Coord.). A crise e o direito. Coimbra: Almedina, 2013. HESPANHA, António Manuel. História das instituições: época medieval e moderna. Coimbra: Almedina, 1982.

HESPANHA, António Manuel. Panorama histórico da cultura jurídica européia. Lisboa: Publicações Europa-América, 1998.

HOBSBAWM, Eric. Historia del siglo XX. Barcelona: Crítica, 1995.

KELSEN, Hans. Teoria pura do direito. Trad. João Baptista Machado. 6. ed. São Paulo: Martins Fontes, 1998.

KUHN, Thomas Samuel. A estrutura das revoluções científicas. São Paulo: Perspectiva, 1997.

LATORRE, Angel. Introdução ao direito. Coimbra: Almedina, 2002.

LOPES, José Reinaldo de Lima. O direito na história: lições introdutórias. São Paulo: Max Limonad, 2002.

MARQUES, Mário Reis. Codificação e paradigmas da modernidade. Coimbra: Coimbra Editora, 2003.

MONCADA, Luís Cabral de. Ensaios sobre a lei. Coimbra: Coimbra Editora, 2002.

MONCADA, Luís Cabral de. Estudos de filosofia do Direito e do Estado. Lisboa: Imprensa NacionalCasa da Moeda, 2004. v. II.

NEVES, A. Castenheira. Fontes do direito: contributo para a revisão do seu problema. Boletim da Faculdade de Direito: Estudos em homenagem aos Prof. Doutores M. Paulo Merêa e G. Braga da Cruz II. Coimbra,1982. v. LVIII. p. 168-285.

NOGUEIRA, José Artur A. Duarte. Lei e poder régio: as Leis de Afonso II. Lisboa: Associação Acadêmica da Faculdade de Direito de Lisboa, 2006.

NOGUEIRA, José Artur A. Objecto e método na história do direito: algumas considerações. In: ASCENSÃO, José de Oliveira (Coord.). Estudos em homenagem ao Prof. Doutor Raúl Ventura. Lisboa: Faculdade de Direito da Universidade de Lisboa, 2003. p. 241-261.

NOGUEIRA, J. Duarte; SANTOS, M. Leite. História do direito português. Sumários desenvolvidos. Lisboa: SPB, 1996. v. 1.

OLLERO, Andrés. Igualdad en la aplicación de la ley y precedente judicial. 2. ed. Madri: Centro de Estudios Políticos y Constitucionales, 2005.

PEREZ-BUSTAMANTE, Rogelio. Historia del derecho español: las fuentes del derecho. Madrid: Dykinson, 1994.

PINTO, Eduardo Vera-Cruz. O futuro da justiça. Lisboa: Nova Vega, 2015.

PRIETO SANCHÍS, Luis. Constitucionalismo y positivismo. 2. ed. México: Fontamara, 1997.

SANTOS, Boaventura de Sousa. Pela mão de Alice: o social e o político na pós-modernidade. 4. ed. São Paulo: Cortez, 1997.

SILVA, Nuno J. Espinosa Gomes da. História do direito português: fontes de direito. Lisboa: Fundação Calouste Gulbenkian, 2000.

TOCQUEVILLE, Alexys de. 0 antigo regime e a revolução. Trad. Yvonne Jean. 4. ed. Brasília: Universidade de Brasília, 1997.

TOMAS Y VALIENTE, Francisco. Manual de historia del derecho español. Madrid: Tecnos, 2001. WIEACKER, Franz. História do direito privado moderno. Lisboa: Fundação Calouste Gulbenkian, 2004.

Recebido em: 03/10/2017

Aprovado em: 24/06/2018 